
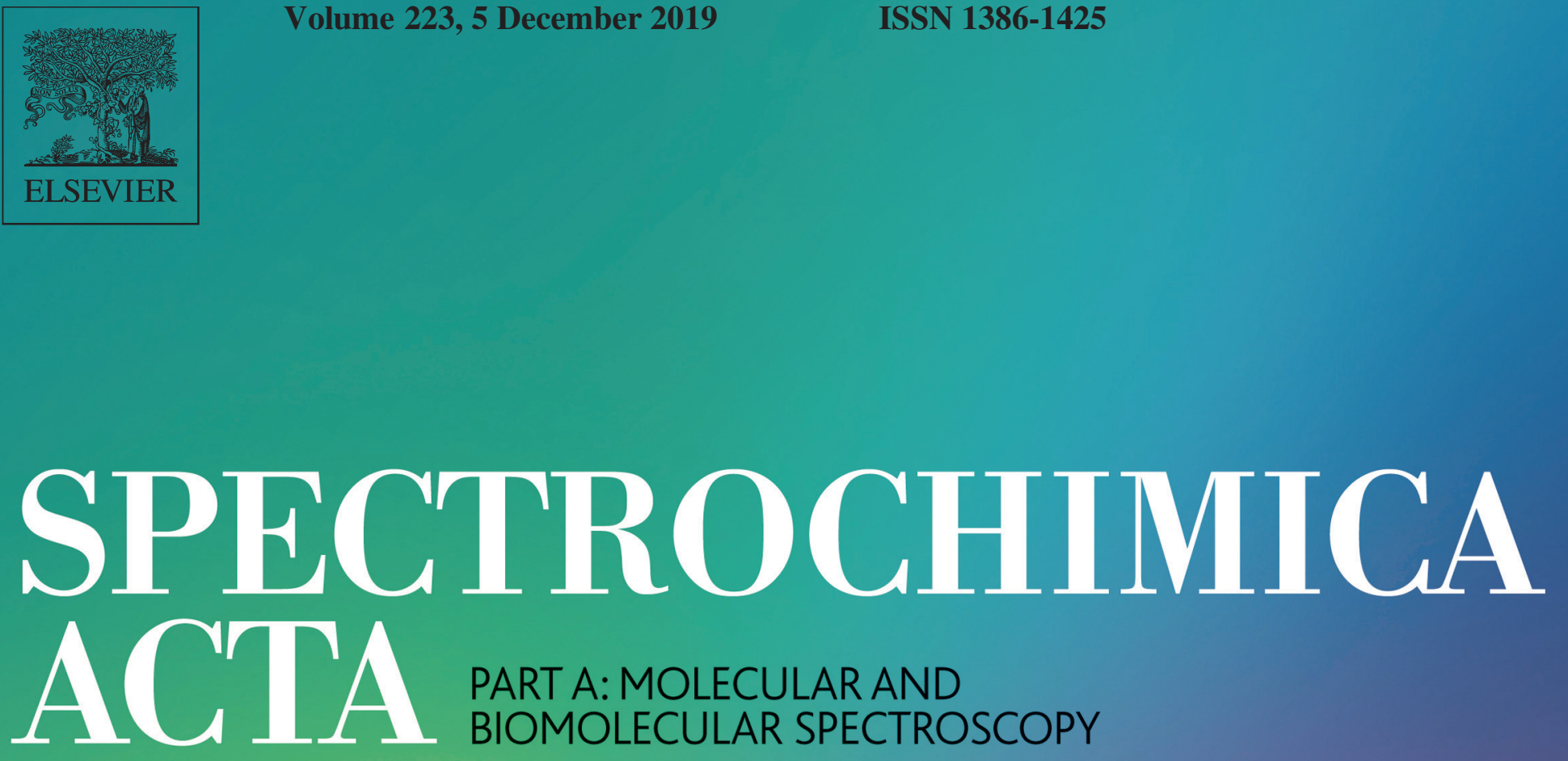

The mechanism of the excited-state proton transfer of Salicylaldehyde azine and 2,2'-[1,4-Phenylenebis $\{(E)$ - nitrilomethylidyne $\}]$ bisphenol: Via single or double proton transfer Hui Zhang, Songsong Liu, Changzhe Zhang, Jianzhong Fan, Lili Lin, Chuankui Wang and Yuzhi Song

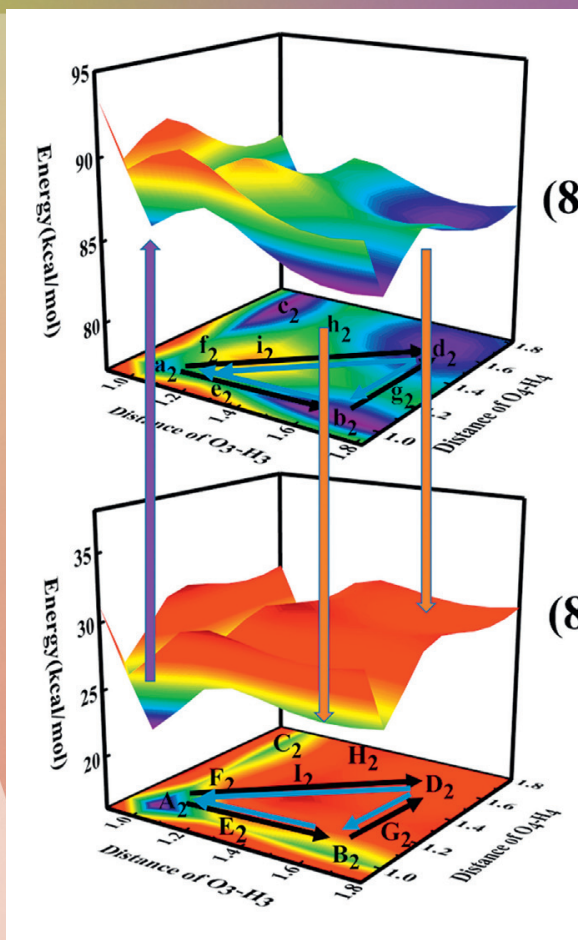

$\mathrm{H}_{2} \mathrm{SPA}$

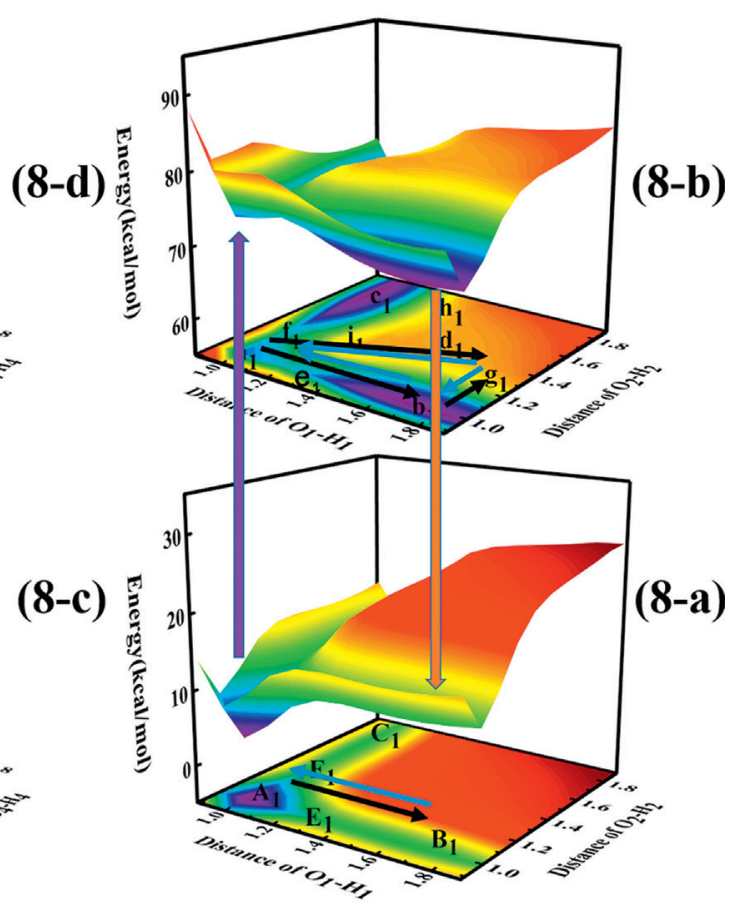

$\mathrm{H}_{2} \mathrm{SA}$ 


\section{EDITORS}

M. Baranska, Jagiellonian University Krakow, Krakow, Poland

J.M. Bowman, Emory University, Atlanta, Georgia, USA

S. Canuto, Universidade de São Paulo (USP), São Paulo, Brazil

J.E. Kim, University of California, San Diego, USA

W. Mäntele, Goethe-Universität Frankfurt, Frankfurt, Germany

B. Ren, Xiamen University, Xiamen, Fujian, China

S. Umapathy, Indian Institute of Science, Bangalore, India

\section{MANAGING EDITOR}

T. Walker

Cappa South, Sixmilebridge, Co Clare, Ireland

\section{EDITORIAL ASSISTANT}

K. Majzner (Assistant for M. Baranska)

Jagiellonian University Krakow, Kraków, Poland

S. Sil (Assistant for S. Umapathy)

Indian Institute of Science, Bangalore, India

\section{EDITORIAL BOARD}

V. Barone, Pisa, Italy

G.J. Blanchard, East Lansing, Michigan, USA

H.J. Byrne, Dublin, Ireland

T. Carrington, Kingston, Ontario, Canada

Z. Chen, Ann Arbor, Michigan, USA

M. Cho, Seoul, South Korea

B.J. Costa Cabral, Lisboa, Portugal

A.G. Császár, Budapest, Hungary

M.P. Gaigeot, Evry, France

R. Goodacre, Institute of Integrative Biology, University of Liverpool, UK

G.A. Guirgis, Charleston, South Carolina, USA

K. Hauser, Konstanz, Germany

P. Hellwig, Strasbourg, France

A.A. Kamnev, Saratov, Russian Federation

T.A. Keiderling, Chicago, Illinois, USA

T. Lian, Atlanta, Georgia, USA

N. Maiti, Mumbai, India

S. Nie, Atlanta, Georgia, USA

R. Pal, Durham, England, UK

A.W. Parker, Oxfordshire, UK

S.P. Perlepes, Patras, Greece

D. Philip, Thiruvananthapuram, India

R. Rivelino, Salvador, Brazil

S. Saha, Varanasi, Uttar Pradesh, India

S. Schlücker, Essen, Germany

D. Sockalingum, Reims, France

A.G. Souza Filho, Fortaleza, Brazil

Z.-Q. Tian, Xiamen, China

G. Turrell, Lille, France

V. Vaida, Boulder, Colorado, USA

P. Vandenabeele, Gent, Belgium

X.S. Zhao, Beijing, China 


\title{
Infrared and Raman spectra of strontium and barium pimelates monohydrates
}

\author{
V. Stefov ${ }^{\mathrm{a}, \mathrm{b}, *}$, V. Koleva $^{\mathrm{c}}$, A. Janevski ${ }^{\mathrm{d}}, \mathrm{G}$. Bogoeva-Gaceva ${ }^{\mathrm{e}, \mathrm{b}}, \mathrm{M}$. Najdoski ${ }^{\mathrm{a}, \mathrm{b}}$ \\ a Institute of Chemistry, Faculty of Natural Sciences and Mathematics, Ss. Cyril and Methodius University, P.O. Box 162, 1001 Skopje, Macedonia \\ ${ }^{\mathrm{b}}$ Research Center for Environment and Materials, Macedonian Academy of Sciences and Arts, 1001 Skopje, Macedonia \\ ' Institute of General and Inorganic Chemistry, Bulgarian Academy of Sciences, 1113 Sofia, Bulgaria \\ ${ }^{d}$ Faculty of Technology, University Goce Delčev, Krste Misirkov bb, 2000 Štip, Macedonia \\ e Faculty of Technology and Metallurgy, Ss. Cyril and Methodius University, Ruger Boskovic 16, 1000 Skopje, Macedonia
}

\section{A R T I C L E I N F O}

\section{Article history:}

Received 10 April 2019

Received in revised form 10 July 2019

Accepted 12 July 2019

Available online 14 July 2019

\section{Keywords:}

Strontium

Barium

Pimelates

Crystallohydrate

Infrared

Raman

\begin{abstract}
A B S T R A C T
The salts of dicarboxylic acids with alkaline earth metals are not very thoroughly studied and only a few such compounds are well known and characterized. In this work a detailed examination of the infrared spectra recorded at room temperature (RT) and at the liquid nitrogen boiling temperature (LNT) and Raman spectra (at room temperature) of the monohydrates of strontium and barium pimelates, $\left[\mathrm{Sr}\left(\mu_{6}-\mathrm{C}_{7} \mathrm{H}_{10} \mathrm{O}_{4}\right)\left(\mathrm{H}_{2} \mathrm{O}\right)\right] \mathrm{n}$ and [Ba $\left.\left(\mu_{6}-\mathrm{C}_{7} \mathrm{H}_{10} \mathrm{O}_{4}\right)\left(\mathrm{H}_{2} \mathrm{O}\right)\right] \mathrm{n}$ respectively, has been carried on. These isostructural salts are important nucleating agents for processing of isotactic polypropylene (iPP). The vibrational spectra of the two salts have been interpreted by using factor group analysis. For more correct and unequivocal interpretation of the vibrational spectra, samples containing partially and almost fully deuterated crystallization water have also been prepared and studied. The effect of the metal ion on the vibrations of the pimelic acid ion as well as the strength of the hydrogen bonds formed by the crystallization water molecule has been discussed.
\end{abstract}

(C) 2019 Elsevier B.V. All rights reserved.

\section{Introduction}

In industrial practice of isotactic polypropylene (iPP), nucleating agents are used routinely to enhance the overall crystallization rate, or to impart improved mechanical or optical properties by reducing polymer's spherulite size. Also, selective nucleating agents have been developed to induce appearance of a certain polymorphic modification ( $\alpha$ or $\beta$ ) and to alter its crystal morphology which, in turn, influences the overall polymer properties.

In our previous work [1] we studied the $\beta$-nucleation ability of $\mathrm{Sr}$ and Ba pimelates, for processing of iPP in a temperature range of interest (above $200^{\circ} \mathrm{C}$ ). It was found that at the melting temperature of iPP, the pimelates of $\mathrm{Sr}$ and $\mathrm{Ba}$ are in crystalline state, and their nucleating activity differs considerably with regards to the cooling rate. This observation was ascribed to the changes in their structure upon heating, i.e. changes in the so called misfit factor that is responsible for epitaxial growth during the crystallization of the polymer on the surfaces of the nucleating agents.

The model of epitaxial crystallization [2,3] is the most frequently used for heterogeneous nucleation of iPP. According to this model, the epitaxial growth of iPP proceeds on the nonpolar part of the molecule

* Corresponding author at: Institute of Chemistry, Faculty of Natural Sciences and Mathematics, Ss. Cyril and Methodius University, P.O. Box 162, 1001 Skopje, Macedonia.

E-mail address: viktorst@pmf.ukim.mk (V. Stefov). of the nucleating agent. The heterogeneous nucleation has been widely analyzed in terms of physical interactions of the polymer and the nucleating agents, and it has been shown that, in the case of matching lattice sizes of the nucleator and the polymer, epitaxial growth of polymers on substrates occur, since the quest polymer chains lie with their chain axis parallel to the substrate surface [3].

In the present paper our interest is focused on strontium and barium salts of pimelic acid (heptane-1,7-dioic acid) with a general formula [ $\mathrm{M}$ $\left.\left(\mu_{6}-\mathrm{C}_{7} \mathrm{H}_{10} \mathrm{O}_{4}\right)\left(\mathrm{H}_{2} \mathrm{O}\right)\right] \mathrm{n}, \mathrm{M}=\mathrm{Sr}$ and $\mathrm{Ba}$. Our goal is to study the vibrational spectra of $\mathrm{Sr}$ and Ba pimelates, in order to determine the structural peculiarities of their active form in the course of isothermal and non-isothermal crystallization processes of iPP. On the other hand, the salts of dicarboxylic acids can form layered or three-dimensional structures known as metal-organic frameworks (MOFs), a new class of materials that are of interest not only in crystal engineering, but also in a wide range of possible practical applications [4-6].

The salts of dicarboxylic acids with alkaline earth metals are very little studied and only a few such compounds are known and characterized mainly by X-ray diffraction methods $[4,7,8]$. The scientific group of W. Lasocha et al. $[4,7,8]$ has prepared and solved the crystal structure of several barium and strontium salts of homologous series of simple dicarboxylic acids $\left(\mathrm{C}_{\mathrm{n}} \mathrm{H}_{2 n}(\mathrm{COOH})_{2}\right)$ where $3 \leq n \leq 10$ (such as adipic, pimelic, suberic, azelaic, dodecanedioic). The available spectroscopic data are also rather scarce. Delabre et al. [9] have reported vibrational spectra of pimelic acid and its potassium salts in crystal state and 